\title{
Mesoscale SST Dynamics in the Kuroshio-Oyashio Extension Region
}

\author{
ZHAO JING \\ Key Laboratory of Physical Oceanography/Institute for Advanced Ocean Studies, Ocean University of China, and \\ Qingdao National Laboratory for Marine Science and Technology, Qingdao, China

\section{PING CHANG} \\ Key Laboratory of Physical Oceanography, Ocean University of China, Ministry of Education, \\ and Pilot National Laboratory for Marine Science and Technology, Qingdao, China, \\ and Department of Oceanography, and Department of Atmospheric Science, \\ Texas A\&M University, College Station, Texas

\section{XuAn Shan, SHENGPENG WANG, AND LiXIN Wu} \\ Key Laboratory of Physical Oceanography/Institute for Advanced Ocean Studies, Ocean University of China, and \\ Qingdao National Laboratory for Marine Science and Technology, Qingdao, China

\section{JAISON KURIAN} \\ Department of Oceanography, Texas A\&M University, College Station, Texas
}

(Manuscript received 3 August 2018, in final form 6 March 2019)

\begin{abstract}
Mesoscale eddies have been extensively studied based on the sea surface height anomaly (SSHA). However, it is the sea surface temperature anomaly (SSTA) that is vital to the mesoscale eddy-atmosphere interactions. In this study, we analyze the amplitude relationship between SSHA and SSTA (referred to as the $\mathrm{H}-\mathrm{T}$ amplitude relationship) in the Kuroshio-Oyashio extension (KOE) region using both observational and reanalysis data. It is found that the spatial distribution of mesoscale SSHA variance is not coincident with mesoscale SSTA variance. The former peaks in the Kuroshio extension around $35^{\circ} \mathrm{N}$ whereas the latter is strongest in the Oyashio extension around $40^{\circ} \mathrm{N}$. Regression analyses indicate that the rate of SSTA change per SSHA change is $1.8^{\circ} \mathrm{C} \mathrm{m}^{-1}$ in the Kuroshio extension $\left(145^{\circ}-160^{\circ} \mathrm{E}, 34^{\circ}-36^{\circ} \mathrm{N}\right)$ but increases drastically by a factor of $3-4$ to $6.2^{\circ} \mathrm{C} \mathrm{m}^{-1}$ in the Oyashio extension $\left(145^{\circ}-160^{\circ} \mathrm{E}, 39^{\circ}-41^{\circ} \mathrm{N}\right)$. A theoretical expression for the $\mathrm{H}-\mathrm{T}$ amplitude relationship is derived. Analyzing this expression suggests that the stronger $\mathrm{H}-\mathrm{T}$ amplitude relationship in the Oyashio extension than the Kuroshio extension is mainly attributed to 1) the smaller thermal expansion coefficient due to the colder background SST, 2) the stronger salinity compensation effect that works against the contribution of SSTA change to sea surface density anomaly (SSDA) change, and 3) the shallower vertical structure of mesoscale eddies. The second factor is ascribed to the strong surface salinity front in the Oyashio extension, while the third factor is found to be qualitatively consistent with the shallower baroclinically unstable modes due to the shallower density front there.
\end{abstract}

\section{Introduction}

Mesoscale eddies ${ }^{1}$ are ubiquitous in the upper ocean, containing $70 \%$ of oceanic kinetic energy (von Storch

\footnotetext{
${ }^{1}$ In this study, oceanic motions at mesoscales are loosely referred to as mesoscale eddies.

Corresponding author: Zhao Jing, jingzhao198763@sina.com
}

et al. 2012). They contribute significantly to the heat transport in the climate system (Jayne and Marotzke 2002; Dong et al. 2014; Zhang et al. 2014) and play an important role in supplying nutrients to the euphotic zone (McGillicuddy et al. 1998; Siegel et al. 1999). In addition, mesoscale eddies are strongly coupled to the atmosphere. On one hand, they exert a profound influence on the atmospheric boundary layer, leaving a significant imprint on local turbulent heat flux, surface 
wind, and rainfall (Chelton et al. 2004; Chelton and Xie 2010; Frenger et al. 2013; Ma et al. 2016; Liu et al. 2018) and further providing a source of influence on the midlatitude weather pattern changes (Ma et al. 2015, 2017). On the other hand, the atmospheric response can in turn affect mesoscale eddies and large-scale circulations in several ways (Gaube et al. 2015; Ma et al. 2016; Byrne et al. 2016). For instance, a recent study (Ma et al. 2016) based on high-resolution coupled climate model simulations demonstrates that the damping of mesoscale eddy potential energy by eddy-induced turbulent heat flux is important in regulating the strength of western boundary currents.

Mesoscale eddy activities are typically inferred based on sea surface height anomaly (SSHA). In the past three decades, global high-resolution SSH observations obtained from the altimeters have revealed pronounced spatial and temporal variations of mesoscale eddies (Stammer 1997, 1998; Chelton et al. 2007, 2011; Itoh and Yasuda 2010; Cheng et al. 2014) and significantly advanced our knowledge of their underlying dynamics (e.g., Qiu 1999; Qiu and Chen 2004, 2010; Scott and Wang 2005; Yang et al. 2018). However, SSHA analyses alone are not always sufficient to understand the ocean mesoscale eddy-atmosphere interaction as this interaction is mediated through mesoscale sea surface temperature anomaly (SSTA) rather than SSHA.

Previous observational studies reveal that there is in general a phase lock between mesoscale SSTA and SSHA in regions of energetic mesoscale activities (Hausmann and Czaja 2012; Frenger et al. 2013; Ma et al. 2016), that is, positive SSHA tends to correspond with positive SSTA and vice versa. However, the amplitude relationship between mesoscale SSHA and SSTA (referred to as the H-T amplitude relationship henceforth) and its controlling factors remain poorly assessed but nevertheless are essential to the understanding of ocean mesoscale eddy-atmosphere interactions. Specifically, whether the H-T amplitude relationship is strongly region-dependent or roughly universal is still unclear.

The Kuroshio-Oyashio extension (KOE) region is a confluence of the western boundary currents of the subtropical and western subarctic gyres to the east of Japan, characterized by complex frontal structures such as the subarctic front (SAF), subarctic boundary (SAB), Kuroshio extension front (KEF), and Kuroshio bifurcation front (KBF) (Iwao et al. 2003; Yasuda 2003). It holds a special place in the study of ocean mesoscale eddy-atmosphere interactions, as mesoscale eddies in this region are not only highly active but also can exert a distant influence on the large-scale atmosphere circulation (Ma et al. 2015, 2017). Mesoscale eddy characteristics, variability, and their underlying dynamics in the KOE region have been extensively studied in the past two decades based on the SSHA (e.g., Qiu and Chen 2005; Itoh and Yasuda 2010; Sasaki and Minobe 2015; Yang et al. 2018). Recently, threedimensional structures of mesoscale eddies in this region are revealed by combining the SSHA and hydrographic measurements (Sun et al. 2017; Dong et al. 2017). It is found that the vertical profiles of temperature and salinity anomalies carried by mesoscale eddies differ significantly between the Kuroshio and Oyashio extensions (Dong et al. 2017), implying an inhomogeneous $\mathrm{H}-\mathrm{T}$ amplitude relationship in the KOE region. However, the dynamical cause for this spatial inhomogeneity has not been systematically analyzed and understood. In this study, it is our attempt to further quantify the inhomogeneous H-T amplitude relationship in the KOE region and shed some light on the underlying dynamics. The rest of the paper is organized as follows. Section 2 describes the data and methodology. Results and analyses are presented in section 3. Conclusions and discussion are provided in section 4 .

\section{Data and methodology}

The SSH observations are obtained from the SSALTO/ Data Unification and Altimeter Combination System (DUACS) multimission altimeter sea level anomaly produced and distributed by the Copernicus Marine and Environment Monitoring Service (CMEMS; http:// www.marine.copernicus.eu). This product merges data from all altimeter missions. The horizontal resolution is $0.25^{\circ}$, and the temporal resolution is one day. The SST data are derived from the NOAA OISST V2 High Resolution Dataset provided by the NOAA/OAR/ ESRL PSD, Boulder, Colorado, from their website https://www.esrl.noaa.gov/psd/ (Reynolds et al. 2007). The product combines satellite and in situ measurements. The data are daily averages with a horizontal resolution of $0.25^{\circ}$. In this study, the SSH and SST data during 2005-14 are used, which should be sufficiently long to obtain robust statistics. To compute the mesoscale anomalies, we first remove the $10-y r$ time mean and then filter out the large spatial scale background field using a $4^{\circ} \times 4^{\circ}$ boxcar moving filter. It is found that in the KOE region such a simple filter yields similar results to those derived from the more sophisticated Loess filter with a $15^{\circ}$ (longitude) $\times 5^{\circ}$ (latitude) halfwidth. The latter has been widely used to isolate the mesoscale eddy variability from the large-scale background field in the KOE region (e.g., Ma et al. 2015, 2016) but carries a high computational burden.

To analyze the controlling mechanisms for the H-T amplitude relationship, the Four-Dimensional Variational 

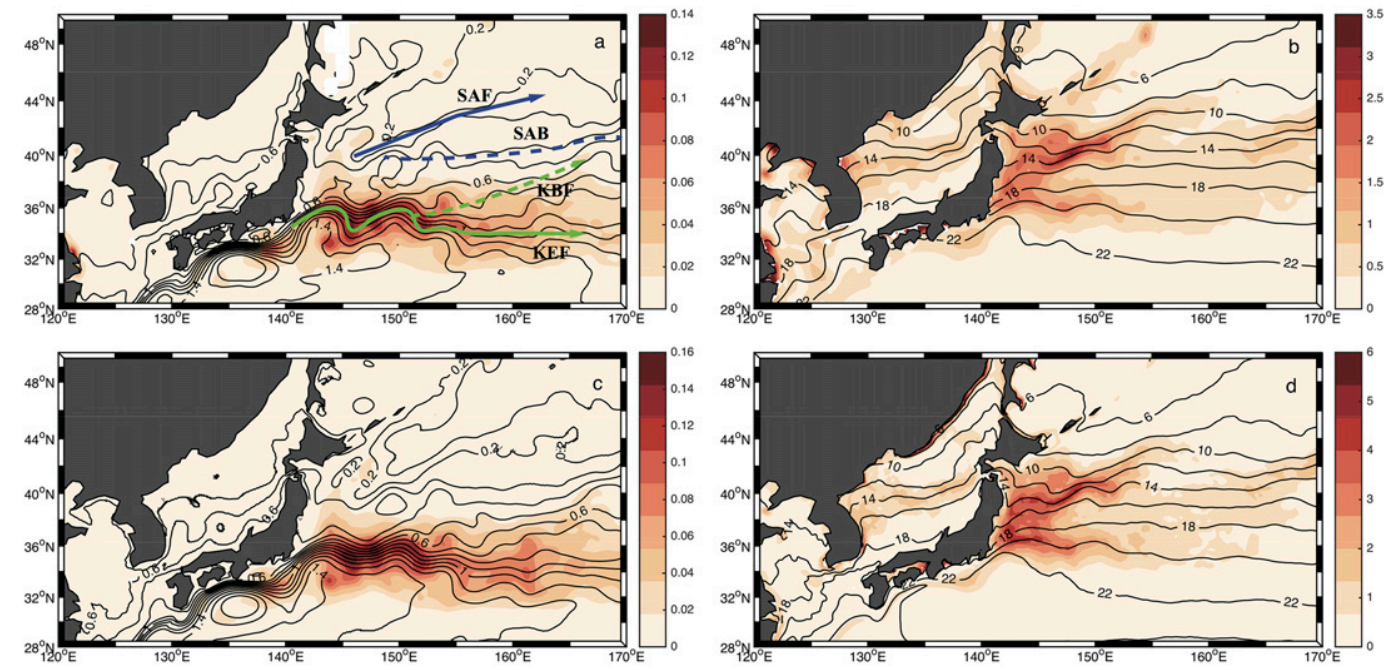

FIG. 1. (a),(c) Mesoscale SSHA variance $\left(\mathrm{m}^{2}\right.$ ) derived from the AVISO and FORA-WNP30. (b),(d) Mesoscale SSTA variance $\left({ }^{\circ} \mathrm{C}^{2}\right)$ derived from the OI SST and FORA-WNP30. Contours in (a) and (c) [(b) and (d)] denote the climatological mean SSH (SST) from observations and reanalysis. The colored lines in (a) mark the positions of Kuroshio extension front (KEF), subarctic front (SAF), subarctic boundary (SAB), and Kuroshio bifurcation front $(\mathrm{KBF})$.

Ocean Reanalysis for the Western North Pacific over 30 Years (FORA-WNP30; Usui et al. 2017) is used. FORAWNP30 reanalysis is produced based on the fourdimensional variational analysis scheme version of the Meteorological Research Institute Multivariate Ocean Variational Estimation system. It assimilates in situ temperature and salinity profiles as well as satellite-measured SST and SSH. The model domain $\left(117^{\circ} \mathrm{E}-160^{\circ} \mathrm{W}, 15^{\circ}-\right.$ $65^{\circ} \mathrm{N}$ ) covers the western North Pacific. The horizontal grid size is variable: the zonal (meridional) resolution is $1 / 10^{\circ}$ from $117^{\circ}$ to $160^{\circ} \mathrm{E}$ (from $15^{\circ}$ to $50^{\circ} \mathrm{N}$ ) and $1 / 6^{\circ}$ from $160^{\circ} \mathrm{E}$ to $160^{\circ} \mathrm{W}$ (from $50^{\circ}$ to $65^{\circ} \mathrm{N}$ ). There are 54 levels in the vertical direction with the layer thickness increasing from $1 \mathrm{~m}$ at the surface to $600 \mathrm{~m}$ at $6300-\mathrm{m}$ depth. The daily output of oceanic temperature, salinity, zonal and meridional velocities, and sea surface height spans from 1982 to 2014 . To be consistent with the period of the observed datasets, only the records within 2005-14 are used.

\section{Results and analyses}

\section{a. The spatial distribution of H-T amplitude relationship in the KOE region}

Figures $1 \mathrm{a}$ and $1 \mathrm{~b}$ display the observed variances of mesoscale SSHA and SSTA in the KOE region, respectively. Consistent with the previous studies (e.g., Qiu and Chen 2010), the strongest mesoscale SSHA variance straddles along the Kuroshio extension centered around $35^{\circ} \mathrm{N}$ where the climatological mean SSH is characterized by the enhanced gradient. However, the energetic mesoscale SSTA variance occurs to the north of $36^{\circ} \mathrm{N}$. Its maximum occurs in the Oyashio extension around $40^{\circ} \mathrm{N}$ with the strongest gradient of climatological mean SST and does not coincide with the maximal mesoscale SSHA variability that gauges eddy strength. What causes this spatial mismatch between mesoscale SSHA and SSTA variances?

To shed light on this question, a scatterplot of mesoscale SSHA versus mesoscale SSTA within $145^{\circ}-160^{\circ} \mathrm{E}$, $32^{\circ}-42.5^{\circ} \mathrm{N}$ encompassing the $\mathrm{KOE}$ region with strong mesoscale SSHA and SSTA variances is shown in Fig. 2a. It is evident that the H-T amplitude relationship is region dependent. In specific, SSTA changes are much less sensitive to SSHA changes in the Kuroshio extension than in the Oyashio extension. It means that even though the mesoscale SSHA variance is higher in the Kuroshio extension, it does not give rise to stronger mesoscale SSTA variability. Therefore, the explanation of the spatial mismatch between mesoscale SSHA and SSTA variances lies in the pronounced spatial inhomogeneity of $\mathrm{H}-\mathrm{T}$ amplitude relationship in the KOE region.

To quantify the H-T amplitude relationship in the Kuroshio extension and Oyashio extension as well as their difference, we perform a regression analysis between mesoscale SSHA and SSTA:

$$
T_{s}^{\prime}=k \eta^{\prime}
$$

where $T_{s}^{\prime}$ denotes the SSTA, $\eta^{\prime}$ represents the SSHA, and the regression coefficient $k$ measures the $\mathrm{H}-\mathrm{T}$ amplitude relationship. Sensitivity tests suggest that 

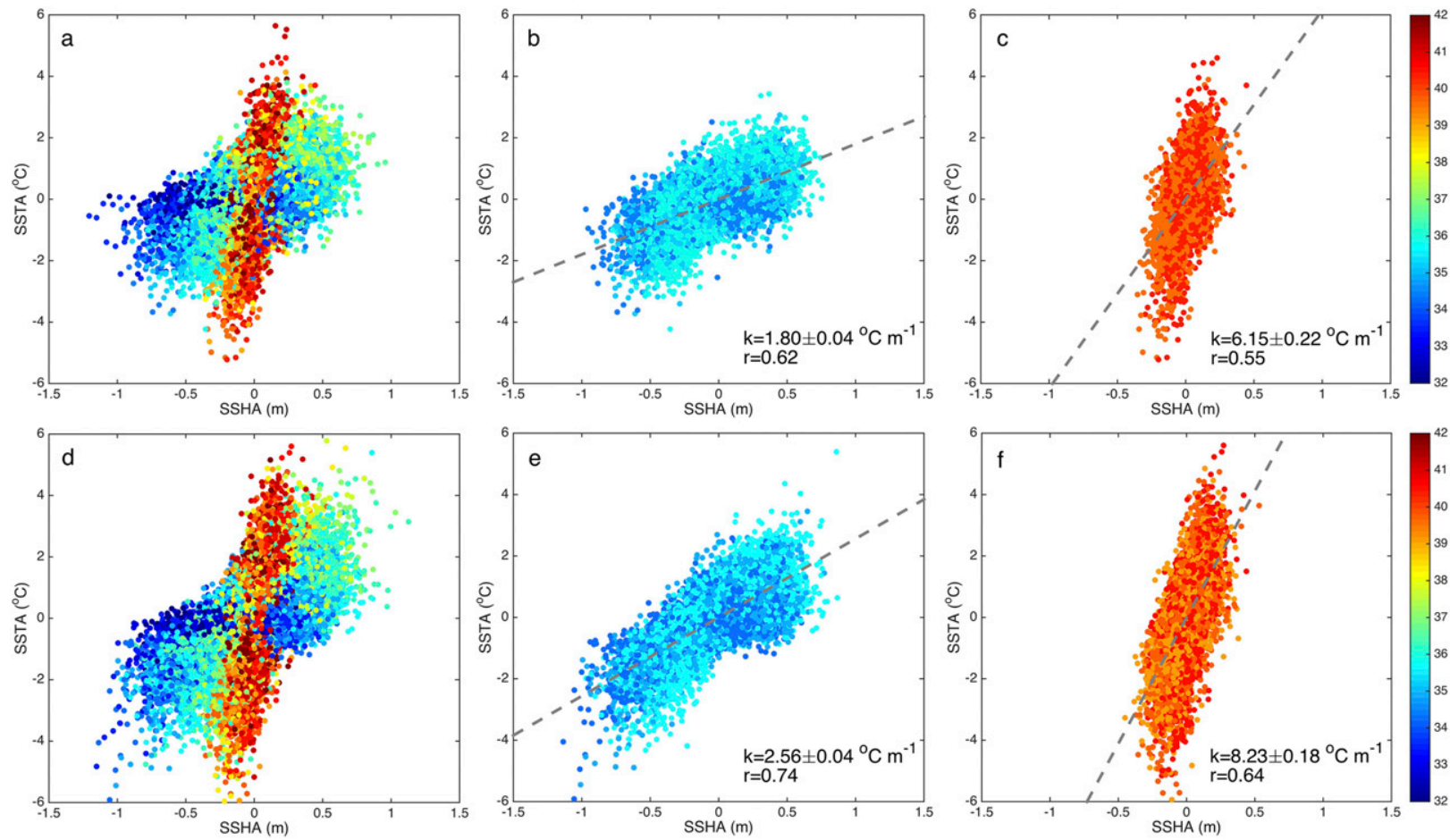

FIG. 2. Scatterplots of mesoscale SSHA vs SSTA in (a) the entire KOE region $\left(145^{\circ}-160^{\circ} \mathrm{E}, 32^{\circ}-42.5^{\circ} \mathrm{N}\right)$, (b) the Kuroshio extension $\left(145^{\circ}-160^{\circ} \mathrm{E}, 34^{\circ}-36^{\circ} \mathrm{N}\right)$, and (c) the Oyashio extension $\left(145^{\circ}-160^{\circ} \mathrm{E}, 39^{\circ}-41^{\circ} \mathrm{N}\right)$ derived from the observations. Parameter $k$ is the regression coefficient with the error bar denoting its $95 \%$ confidence interval, and $r$ is the correlation coefficient. The color denotes the latitude. (d)-(f) As in (a)-(c), but derived from FORA-WNP30.

including the intercept in the regression model does not have any significant impact on the estimates of $k$. Figures $2 \mathrm{~b}$ and $2 \mathrm{c}$ display the scatterplots of mesoscale SSHA versus mesoscale SSTA in the Kuroshio extension $\left(145^{\circ}-160^{\circ} \mathrm{E}, 34^{\circ}-36^{\circ} \mathrm{N}\right)$ and Oyashio extension $\left(145^{\circ}-160^{\circ} \mathrm{E}, 39^{\circ}-41^{\circ} \mathrm{N}\right)$ as well as the associated regression coefficients. Consistent with previous analysis (Hausmann and Czaja 2012; Frenger et al. 2013; Ma et al. 2016), there is in general a phase lock between mesoscale SSHA and SSTA, as evidenced by their strong positive correlation. The correlation coefficient between mesoscale SSHA and SSTA is 0.62 in the Kuroshio extension and 0.55 in the Oyashio extension (statistically significant at $99 \%$ significance level). In contrast, the value of $k$ in the Kuroshio extension is $1.8^{\circ} \mathrm{Cm}^{-1}$, only $1 / 4-1 / 3$ of the value $6.2^{\circ} \mathrm{Cm}^{-1}$ in the Oyashio extension. The large discrepancy between $k$ in the Kuroshio extension and Oyashio extension explains the spatial mismatch of mesoscale SSHA and SSTA variances.

\section{b. Causes of the difference in H-T amplitude relationship between the Kuroshio extension and Oyashio extension}

In this subsection, we examine the causes for the different H-T amplitude relationships between Kuroshio extension and Oyashio extension using the 3D data from the FORA-WNP30 reanalysis. This reanalysis dataset well reproduces the observed mean field and mesoscale activities in the KOE region, including the spatial distribution of mesoscale SSHA and SSTA variances despite that their magnitudes are systematically larger probably due to the finer horizontal resolution of the reanalysis model (Fig. 1). Moreover, it successfully reproduces the distinct $\mathrm{H}-\mathrm{T}$ amplitude relationships in the Kuroshio extension and Oyashio extension. The simulated values of $k$ in the Kuroshio extension and Oyashio extension are $2.6^{\circ}$ and $8.2^{\circ} \mathrm{Cm}^{-1}$, respectively, close to (but higher than) those $\left(1.8^{\circ}\right.$ and $\left.6.2^{\circ} \mathrm{Cm}^{-1}\right)$ derived from the observations (Fig. 2). These agreements give us the confidence on the validity of using the FORAWNP30 reanalysis to examine the underlying dynamics of H-T amplitude relationship in the KOE region.

The starting point of the diagnostic analysis is the hydrostatic approximation that is well satisfied by mesoscale eddies due to their small aspect ratio:

$$
p(x, y, z, t)=p_{\text {air }}(x, y, t)+\int_{z}^{\eta} \rho(x, y, s, t) g d s,
$$

where $p$ is the seawater pressure, $p_{\text {air }}$ the air pressure at the sea surface, $\rho$ the seawater density, $g$ the gravity 
acceleration, and $s$ the integration variable corresponding to the vertical coordinate. Given that the seawater density changes only by less than a few percent in the real ocean, Eq. (2) can be approximated as

$$
p=p_{\text {air }}+\int_{z}^{0} \rho g d s+\rho_{0} g \eta,
$$

where $\rho_{0}=1025 \mathrm{~kg} \mathrm{~m}^{-3}$ is the reference density. Taking the mesoscale anomaly on both sides of Eq. (3) yields

$$
p^{\prime}=p_{\mathrm{air}}^{\prime}+\int_{z}^{0} \rho^{\prime} g d s+\rho_{0} g \eta^{\prime}
$$

We make two additional assumptions to further simplify the equation. First, it is assumed that the magnitude of $p_{\text {air }}^{\prime}$ is much smaller than the last two terms on the right-hand side of Eq. (4). Second, we assume that there is a depth $z_{r}$ below which $p^{\prime}$ is close to zero. The first assumption requires that $p^{\prime}$ in the ocean interior is mainly generated by oceanic processes. The second assumption requires that mesoscale eddies are confined in the upper ocean and are very weak in the abyssal ocean. Under these two assumptions, $\eta^{\prime}$ can be approximated as

$$
\eta^{\prime} \approx-\int_{z_{r}}^{0} \rho^{\prime} d s / \rho_{0}
$$

Equation (5) establishes a relationship between mesoscale SSHA and density anomaly. Its validity is demonstrated in Table 1 with $z_{r}$ set at $-2000 \mathrm{~m}$. In both the Kuroshio extension and Oyashio extension, $\eta^{\prime}$ is highly correlated to $-\int_{z_{r}}^{0} \rho^{\prime} d s / \rho_{0}$ with a correlation coefficient of above 0.94 . The regression coefficient $\lambda$ between $\eta^{\prime}$ and $-\int_{z_{r}}^{0} \rho^{\prime} d s / \rho_{0}$ is 1.10 in the Kuroshio extension and 1.08 in the Oyashio extension, close to its theoretical expectation, that is, unity, from Eq. (5). The small positive bias might be due to the contribution from $p_{\text {air }}^{\prime}$ or due to the penetration of mesoscale variability into the region below $z_{r}$. We find that the latter is minor as using $z_{r}=-3000 \mathrm{~m}$ only makes a marginal improvement (Table 1). For instance, the regression coefficient in the Kuroshio extension is only decreased from 1.10 for $z_{r}=-2000 \mathrm{~m}$ to 1.09 for $z_{r}=-3000 \mathrm{~m}$.

Define $F_{V}=\rho^{\prime} / \rho_{s}^{\prime}$, where $\rho_{s}^{\prime}$ is the mesoscale sea surface density anomaly (SSDA), and $F_{V}$ can be regarded as a nondimensional vertical structure function. Substituting $F_{V}=\rho^{\prime} / \rho_{s}^{\prime}$ into Eq. (5) yields

$$
\eta^{\prime}=-\frac{\rho_{s}^{\prime}}{\rho_{0}} H_{e}
$$

TABLE 1. Validation of Eq. (5) in the Kuroshio and Oyashio extensions for $z_{r}=-2000 \mathrm{~m}$ and $z_{r}=-3000 \mathrm{~m}$. Here, $\lambda$ is the regression coefficient between $\eta^{\prime}$ and $-\int_{z_{r}}^{0} \rho^{\prime} d s / \rho_{0}$ while $r$ is the correlation coefficient between the two variables.

\begin{tabular}{lcc}
\hline \hline & Kuroshio & Oyashio \\
\hline$z_{r}=-2000 \mathrm{~m}$ & & \\
$\lambda$ & 1.10 & 1.08 \\
$r$ & 0.97 & 0.94 \\
$z_{r}=-3000 \mathrm{~m}$ & & \\
$\lambda$ & 1.09 & 1.07 \\
$r$ & 0.98 & 0.95 \\
\hline
\end{tabular}

where $H_{e}=\int_{z_{r}}^{0} F_{V} d s$ and its value tends to be larger when mesoscale eddies have a deeper structure, that is, the mesoscale density anomaly peaks at greater depth with relatively weaker surface signals. A cautionary note should be made regarding the interpretation of $H_{e}$ : although $H_{e}$ is related to the vertical extent of mesoscale eddies, it cannot be simply interpreted as a direct measurement of eddy depth. Appendix A provides more detailed discussion between $H_{e}$ and eddy vertical structure.

Combining the linearized equation of state $\rho_{s}^{\prime}=-\rho_{0}\left(\alpha T_{s}^{\prime}-\beta S_{s}^{\prime}\right)$, where $S_{s}^{\prime}$ is the mesoscale sea surface salinity anomaly (SSSA), $\alpha$ is the thermal expansion coefficient, and $\beta$ is the saline contraction coefficient, Eq. (6) can be rewritten as

$$
\eta^{\prime}=\left(\alpha T_{s}^{\prime}-\beta S_{s}^{\prime}\right) H_{e} .
$$

Equation (7) relates the mesoscale SSHA to SSTA. Assuming that the SSTA and SSSA were independent from each other, $k$ would be equal to $k=\alpha^{-1} H_{e}^{-1}$. However, in the real ocean, temperature and salinity anomalies typically do not evolve independently from each other but are strongly correlated. This is because the temperature and salinity are to some extent conserved during the fluids motion so that anomalies of both quantities depend on the fluids trajectory, making them correlated. Indeed, there is significant correlation between the mesoscale SSTA and SSSA in the KOE region. Their correlation coefficient reaches up to 0.74 and 0.89 in the Kuroshio extension and Oyashio extension (statistically significant at $99 \%$ significance level), respectively. To account for this tight relationship between mesoscale SSTA and SSSA, we introduce an effective thermal expansion coefficient $\alpha_{\text {eff }}$ defined as

$$
\rho_{s}^{\prime} / \rho_{0}=-\alpha_{\mathrm{eff}} T_{s}^{\prime}
$$

In practice, $\alpha_{\text {eff }}$ can be estimated from the regression analysis based on Eq. (8). Moreover, assuming that 1) the meridional component of background temperature 

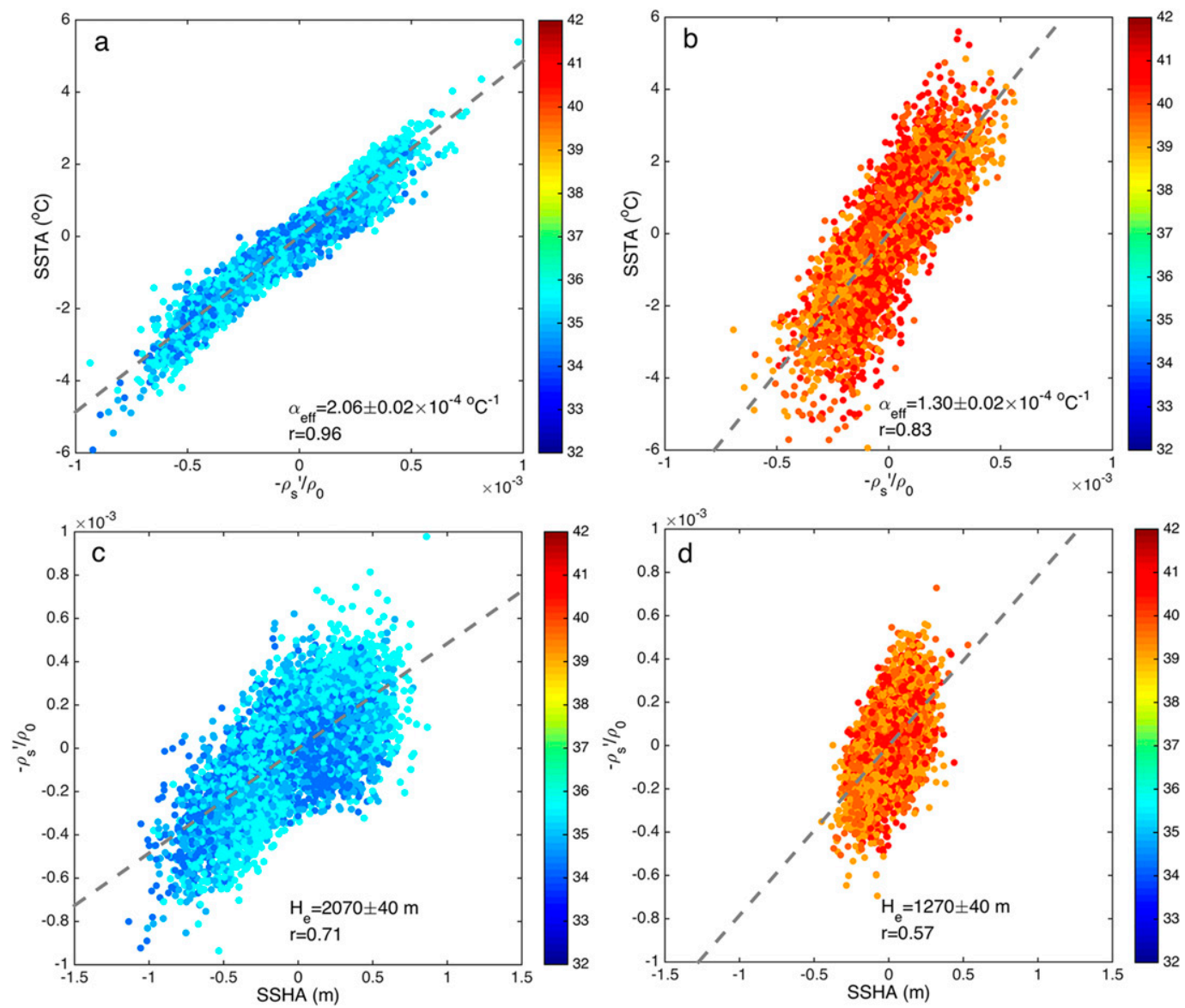

FIG. 3. Scatterplots of mesoscale $-\rho_{s}^{\prime} / \rho_{0}$ vs SSTA in (a) the Kuroshio extension $\left(145^{\circ}-160^{\circ} \mathrm{E}, 34^{\circ}-36^{\circ} \mathrm{N}\right)$ and (b) the Oyashio extension $\left(145^{\circ}-160^{\circ} \mathrm{E}, 39^{\circ}-41^{\circ} \mathrm{N}\right)$ derived from the FORA-WNP30. The color denotes the latitude. Parameter $r$ is the correlation coefficient, and $\alpha_{\text {eff }}$ is computed as the reciprocal of regression coefficient with the error bar denoting its $95 \%$ confidence interval. (c),(d) As in (a) and (b), but for scatterplots of mesoscale SSHA vs $-\rho_{s}^{\prime} / \rho_{0}$. Note that $H_{e}$ is equal to the reciprocal of regression coefficient.

and salinity gradient dominates over the zonal component and 2) fluids motion at the sea surface is nearly horizontal and adiabatic, the value of $\alpha_{\text {eff }}$ can also be theoretically derived as follows (see appendix B for details):

$$
\alpha_{\text {eff }}=\alpha-\beta \frac{\partial \bar{S}_{s}}{\partial y} / \frac{\partial \bar{T}_{s}}{\partial y}
$$

where the overbar denotes the background field. When $\partial \bar{T}_{s} / \partial y$ and $\partial \bar{S}_{s} / \partial y$ have the same sign, the contribution of SSTA to SSDA will be partially cancelled by the contribution of SSSA so that $\alpha_{\text {eff }}$ will be smaller than $\alpha$. The opposite is true when $\partial \bar{T}_{s} / \partial y$ and $\partial \bar{S}_{s} / \partial y$ have different signs. To distinguish $\alpha_{\text {eff }}$ derived from Eq. (8) based on the regression analysis and from the theoretical solution Eq. (9), we use $\alpha_{\text {eff }}^{t}$ to denote the latter henceforth.

Combining Eqs. (8) and (6) yields the final expression for $k$ :

$$
k=\alpha_{\text {eff }}^{-1} H_{e}^{-1} .
$$

Equation (10) indicates that $k$ is inversely proportional to $\alpha_{\text {eff }}$ and $H_{e}$. In the following analysis, we will use Eq. (10) as a diagnostic tool to explore the underlying reasons for the different $\mathrm{H}-\mathrm{T}$ amplitude relationships between the Kuroshio extension and Oyashio extension.

Figures $3 \mathrm{a}$ and $3 \mathrm{~b}$ display the scatterplots of mesoscale SSDA versus SSTA in the Kuroshio extension and Oyashio extension as well as the values of $\alpha_{\text {eff }}$ derived from the regression analysis based on Eq. (8). There is significant difference between $\alpha_{\text {eff }}$ in the Kuroshio extension and Oyashio extension. The value of $\alpha_{\text {eff }}$ in the Kuroshio extension is $2.1 \times 10^{-4}{ }^{\circ} \mathrm{C}^{-1}$, about twice the value of $1.3 \times 10^{-4}{ }^{\circ} \mathrm{C}^{-1}$ in the Oyashio extension. Therefore, the difference of $\alpha_{\text {eff }}$ accounts for about $50 \%$ of the difference of $k$ (a factor of 3-4) between the Kuroshio extension and Oyashio extension. 

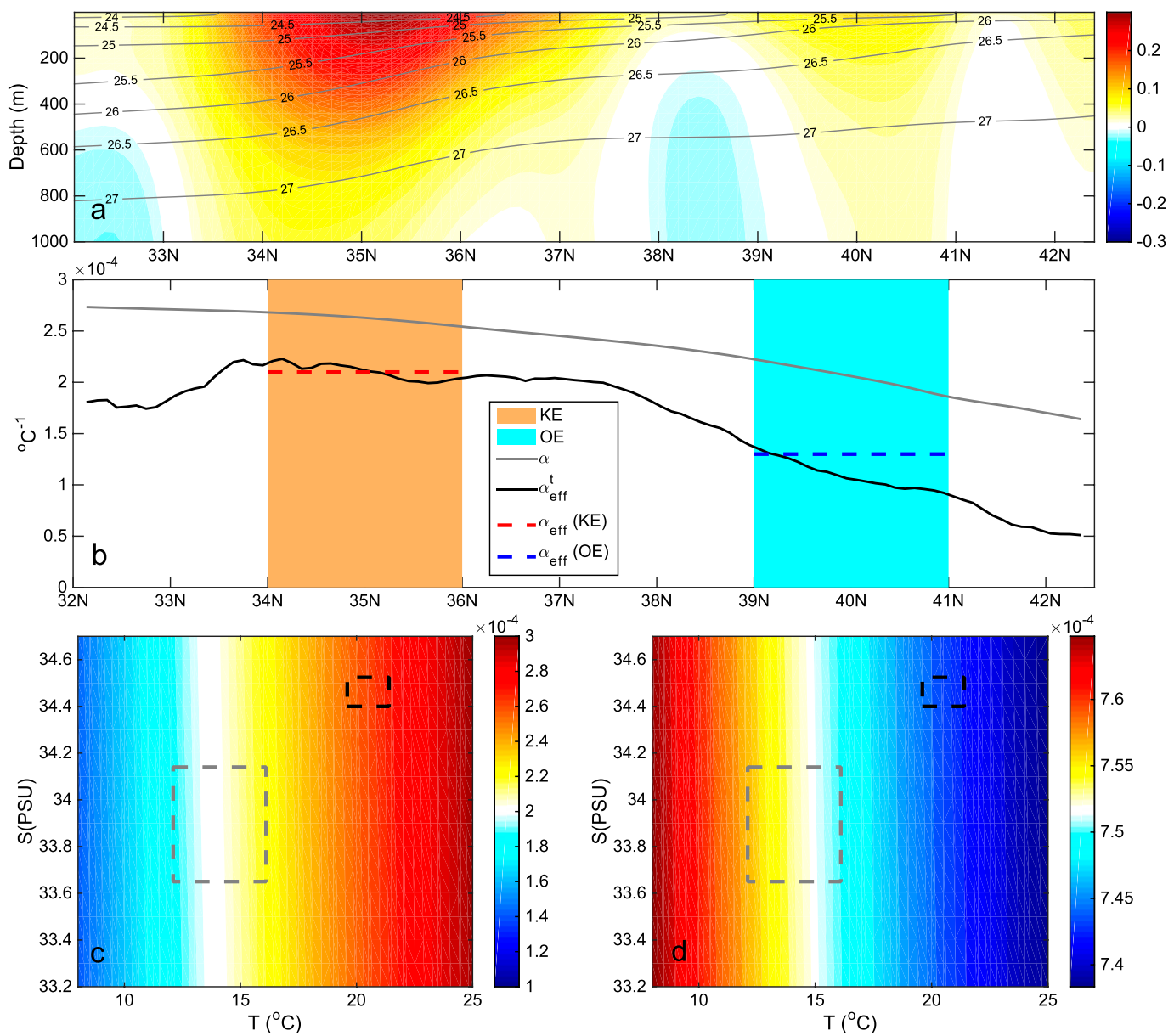

FIG. 4. (a) Zonal mean flow $\left(\mathrm{m} \mathrm{s}^{-1}\right.$ ) between $145^{\circ}$ and $160^{\circ} \mathrm{E}$ (color). Contours denote the zonally averaged isopycnals. (b) The latitudinal distribution of $\alpha$ (gray solid) and $\alpha_{\text {eff }}^{t}$ (black solid) derived from Eq. (9). The shadings denote the Kuroshio extension and Oyashio extension with energetic zonal flow. The red and blue dashed lines denote the value of $\alpha_{\text {eff }}$ estimated from the regression analysis using Eq. (8). (c) The dependence of $\alpha\left({ }^{\circ} \mathrm{C}^{-1}\right)$ on temperature and salinity. The black and gray boxes encompass the temperature and salinity ranges in the Kuroshio extension and Oyashio extension, respectively. (d) As in (c), but for $\beta\left(\mathrm{psu}^{-1}\right)$. All the results are based on the FORA-WNP30 reanalysis data.

The values of $\alpha_{\text {eff }}$ in the Kuroshio extension and Oyashio extension derived from the regression analysis agree reasonably well with $\alpha_{\text {eff }}^{t}$ (Figs. 4a,b), lending supports to the validity of theoretical expression Eq. (9). Equation (9) suggests that the difference of $\alpha_{\text {eff }}$ between the Kuroshio extension and Oyashio extension could be resulted from two aspects. The first one is the dependence of $\alpha$ on temperature, that is, the density change is less sensitive to temperature change for colder seawater than warmer seawater. While the value of $\beta$ is almost a constant for the temperature and salinity range in the KOE region, the value of $\alpha$ differs significantly between the Kuroshio extension and Oyashio extension due to the temperature difference (Figs. 4c,d). The background SST in the Kuroshio extension is in general $7^{\circ} \mathrm{C}$ warmer than that in the Oyashio extension. Accordingly, the value of $\alpha$ $\left(2.6 \times 10^{-4}{ }^{\circ} \mathrm{C}^{-1}\right)$ in the Kuroshio extension is about $30 \%$ larger than that $\left(2.1 \times 10^{-4}{ }^{\circ} \mathrm{C}^{-1}\right)$ in the Oyashio extension. The second aspect is the compensation effect on $\alpha_{\text {eff }}$ due to salinity changes as shown in Eq. (9). In the KOE region, both the values of $\bar{T}_{s}$ and $\bar{S}_{s}$ decrease monotonically as the latitude increases (Fig. 5) so that the contribution of SSTA to SSDA is partially cancelled by the contribution of SSSA. However, this salinity compensation effect is more evident in the Oyashio extension than in the Kuroshio extension (Fig. 4b) due to the strong surface salinity front in the Oyashio extension (Fig. 5e). The value of $\beta\left(\partial \bar{S}_{s} / \partial y\right) /\left(\partial \bar{T}_{s} / \partial y\right)$ in the Kuroshio extension is about $0.5 \times 10^{-4}{ }^{\circ} \mathrm{C}^{-1}$, but increases to about $0.8 \times 10^{-4}{ }^{\circ} \mathrm{C}^{-1}$ in the Oyashio extension region. Combing these two effects leads to the pronounced reduction of $\alpha_{\text {eff }}$ in the Oyashio extension. 

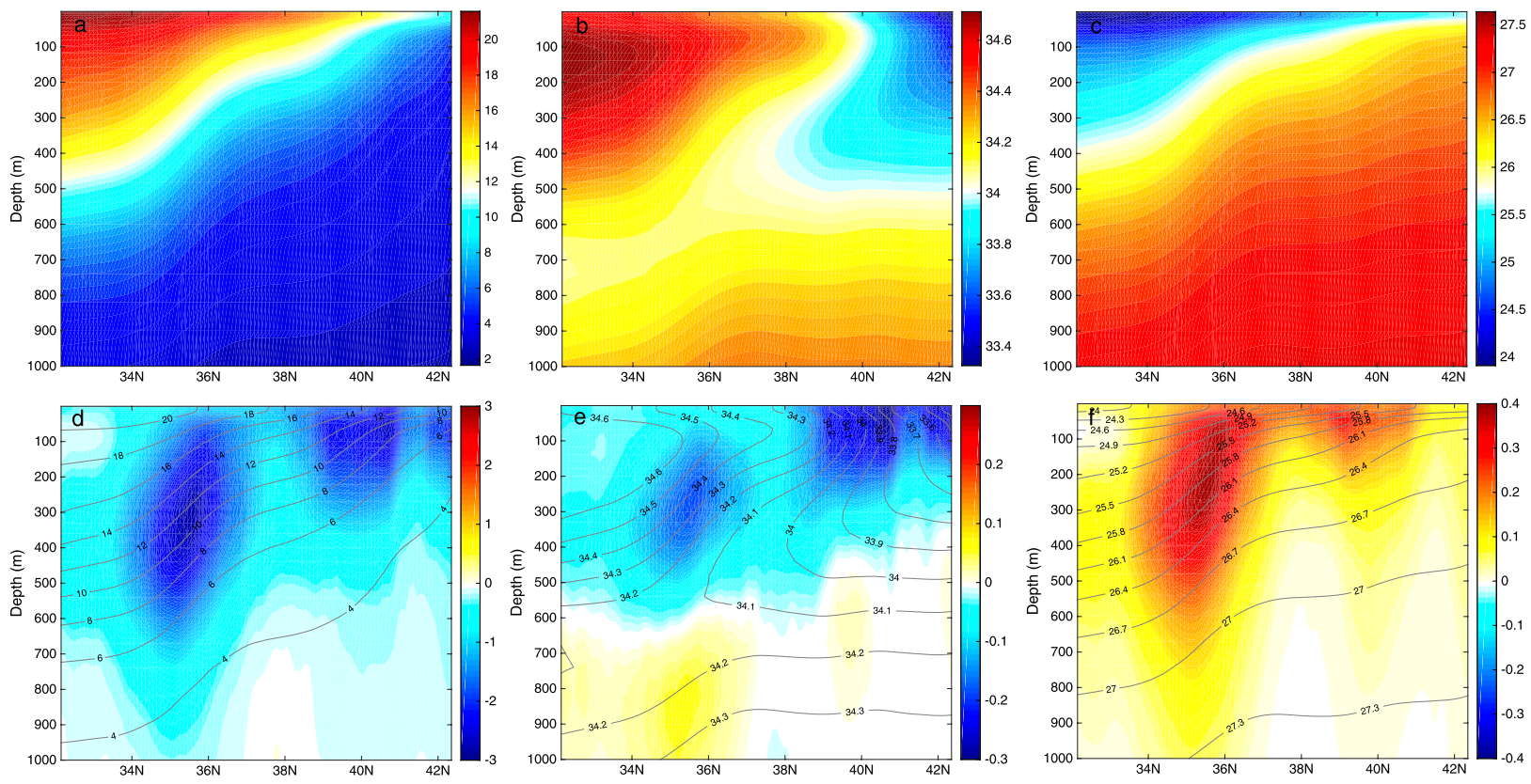

FIG. 5. The zonal mean $\left(145^{\circ}-160^{\circ} \mathrm{E}\right)(\mathrm{a})$ temperature $\left({ }^{\circ} \mathrm{C}\right)$, (b) salinity (psu), (c) density $\left(\mathrm{kg} \mathrm{m}^{-3}\right)$, (d) meridional temperature gradient $\left({ }^{\circ} \mathrm{C}\right.$ per degree of latitude), (e) meridional salinity gradient (PSU per degree of latitude), and (f) meridional density gradient $\left(\mathrm{kg} \mathrm{m}^{-3}\right.$ per degree of latitude). Contours in (d)-(f) correspond to the isolines in (a)-(c), respectively. All the results are based on the FORA-WNP30 reanalysis data.

It should be noted that the difference in $\alpha_{\text {eff }}$ is not sufficient to account for the difference in $k$. The remaining contribution to the difference in $k$ is attributed to the different vertical structures of mesoscale eddies between the Kuroshio extension and Oyashio extension. Figures $3 c$ and $3 d$ display the scatterplots of mesoscale SSHA versus SSDA in the Kuroshio extension and Oyashio extension as well as the values of $H_{e}$ derived from the regression analysis based on Eq. (6). Consistent with Eq. (6), there is high correlation between mesoscale SSHA and SSDA in both the Kuroshio extension and Oyashio extension. But the value of $H_{e}$ in the Kuroshio extension is around $2070 \mathrm{~m}$, about twice the value of $1270 \mathrm{~m}$ in the Oyashio extension. Therefore, the difference in $H_{e}$ accounts for the remaining $50 \%$ of the difference in $k$ between the Kuroshio extension and Oyashio extension.

The larger value of $H_{e}$ in the Kuroshio extension implies a deeper vertical structure of mesoscales eddies with relatively weaker surface signals in that region. This is confirmed by the reanalysis data: the variance of mesoscale density anomaly exhibits a broad peak between 100 and $400 \mathrm{~m}$ in the Kuroshio extension whereas it peaks around $50 \mathrm{~m}$ in the Oyashio extension (Fig. 6). We note that the differed vertical structures of mesoscale eddies in the Kuroshio extension and Oyashio extension were also reported in a recent observational study based on the Argo floats (Dong et al. 2017), lending further supports to our analysis.

It remains to be answered what causes the vertical structure difference between mesoscale eddies in the Kuroshio extension and Oyashio extension. One possible explanation may be drawn from the different vertical positions of the density front between the Kuroshio extension and Oyashio extension (Fig. 5f), assuming that mesoscale eddies located in each of these regions are generated locally through baroclinic instability. Indeed, it is found that the depth of mesoscale density anomaly variance maximum in each region agrees remarkably well with that of the density front (Figs. 5f, 6b). The density front in the Kuroshio extension is significantly deeper than that in the Oyashio extension, which might account for a larger value of $H_{e}$ in the Kuroshio extension. To further test this conjecture, we perform a linear baroclinic instability analysis under the quasigeostrophic (QG) regime:

$$
\frac{\partial q^{\prime}}{\partial t}+U \frac{\partial q^{\prime}}{\partial x}+\frac{\partial \psi^{\prime}}{\partial x} \frac{\partial Q}{\partial y}=0, \quad-H<z<0
$$

$\frac{\partial}{\partial t} \frac{\partial \psi^{\prime}}{\partial z}+U \frac{\partial^{2} \psi^{\prime}}{\partial x \partial z}-\frac{\partial \psi^{\prime}}{\partial x} \frac{\partial U}{\partial z}=0, \quad z=0,-H$

where $q^{\prime}=\partial^{2} \psi^{\prime} / \partial x^{2}+\partial^{2} \psi^{\prime} / \partial y^{2}+(\partial / \partial z)\left[\left(f_{0}^{2} / N^{2}\right)\left(\partial \psi^{\prime} / \partial z\right)\right]$ is the $\mathrm{PV}$ perturbation with $\psi^{\prime}$ the perturbed 

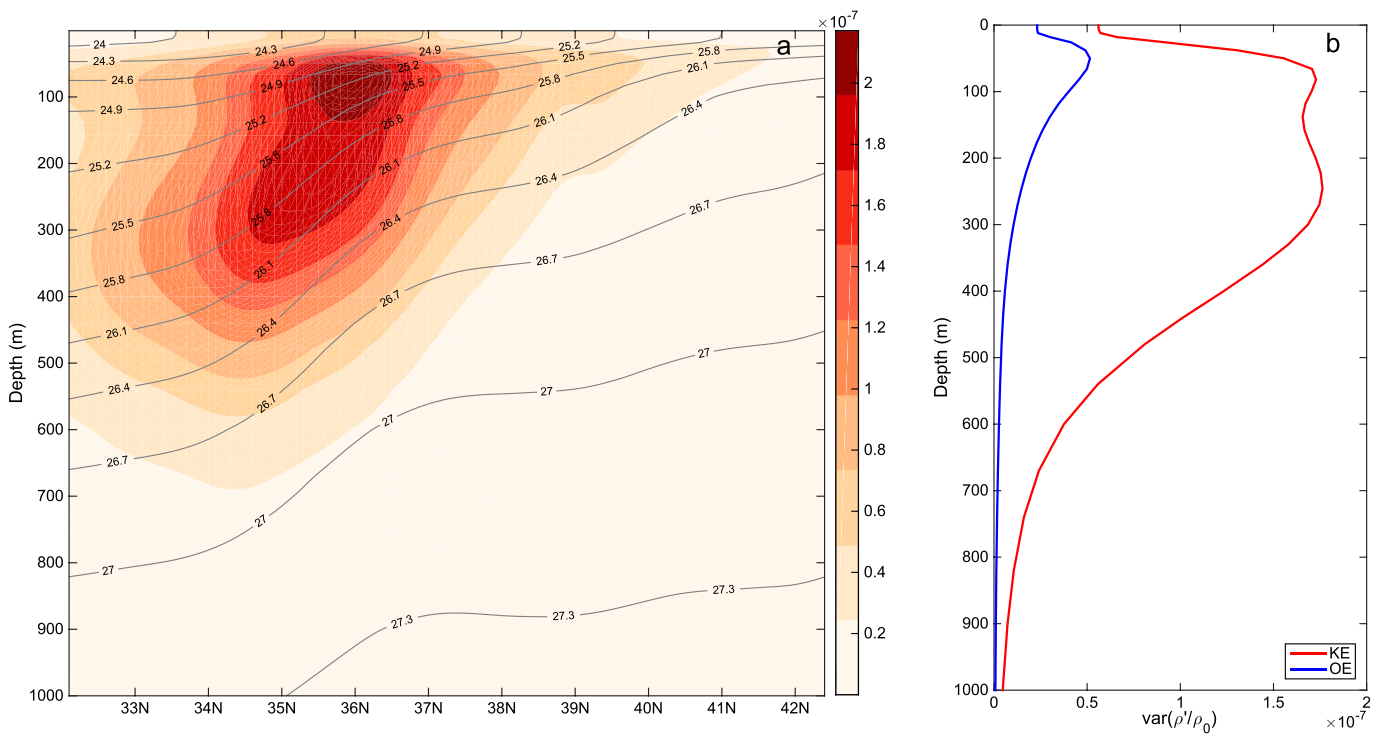

FIG. 6. (a) The variance of $\rho^{\prime} / \rho_{0}$ averaged within $145^{\circ}-160^{\circ} \mathrm{E}$ (color). Contours denote the zonally averaged isopycnals. (b) The vertical profiles of variance of $\rho^{\prime} / \rho_{0}$ in the Kuroshio extension $\left(145^{\circ}-160^{\circ} \mathrm{E}, 34^{\circ}-36^{\circ} \mathrm{N}\right.$; red solid) and Oyashio extension $\left(145^{\circ}-160^{\circ} \mathrm{E}, 39^{\circ}-41^{\circ} \mathrm{N}\right.$; blue solid).

streamfunction, $f_{0}$ the reference Coriolis parameter, $N$ the background buoyancy frequency, $H$ the water depth, and $\partial Q / \partial y=d f / d y-(d / d z)\left[\left(f_{0}^{2} / N^{2}\right)(d U / d z)\right]$ the meridional gradient of background PV. Here the background flow is simplified as a zonally directed flow $U(z)$ with no horizontal variations. This neglects the generation of mesoscale eddies by the barotropic instability that is less important in this region (Yang et al. 2018). The most unstable mode is found by substituting $\psi^{\prime}=$ $\Pi(z) e^{i(k x+l y-\sigma t)}$ into Eqs. (11) and (12) with the meridional wavenumber $l$ set zero (Vallis 2017).

Figure 7 displays the vertical profiles of $U$ and $N^{2}$ averaged in the Kuroshio extension and Oyashio extension for different seasons. Both $N^{2}$ and $U$ exhibit pronounced seasonality. Figure 8 displays the growth rate as a function of zonal wavenumber $k$ and the
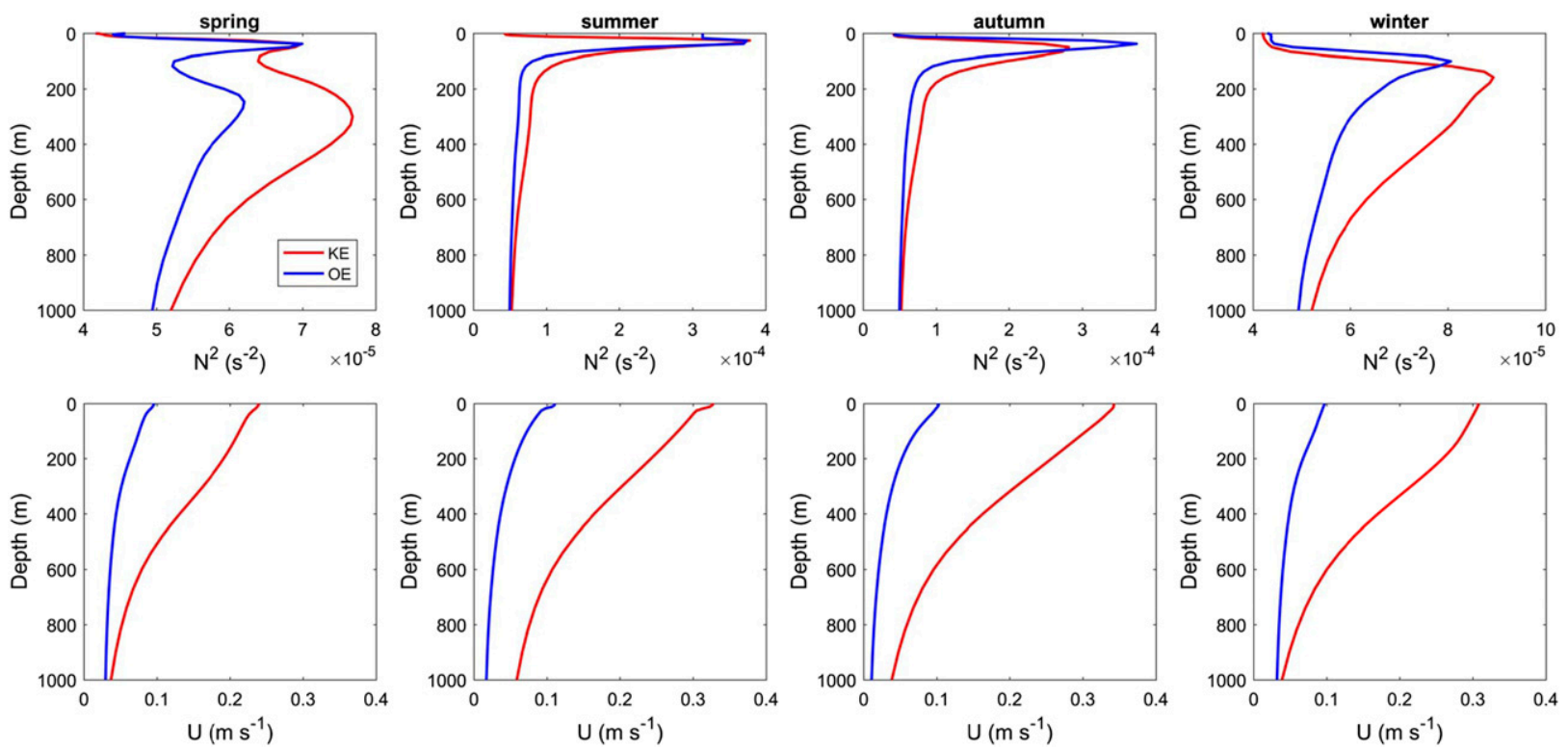

FIG. 7. The vertical profiles of $U(z)$ and $N^{2}(z)$ averaged in the Kuroshio extension $\left(145^{\circ}-160^{\circ} \mathrm{E}, 34^{\circ}-36^{\circ} \mathrm{N}\right)$ and Oyashio extension $\left(145^{\circ}-\right.$ $\left.160^{\circ} \mathrm{E}, 39^{\circ}-41^{\circ} \mathrm{N}\right)$ for different seasons. 

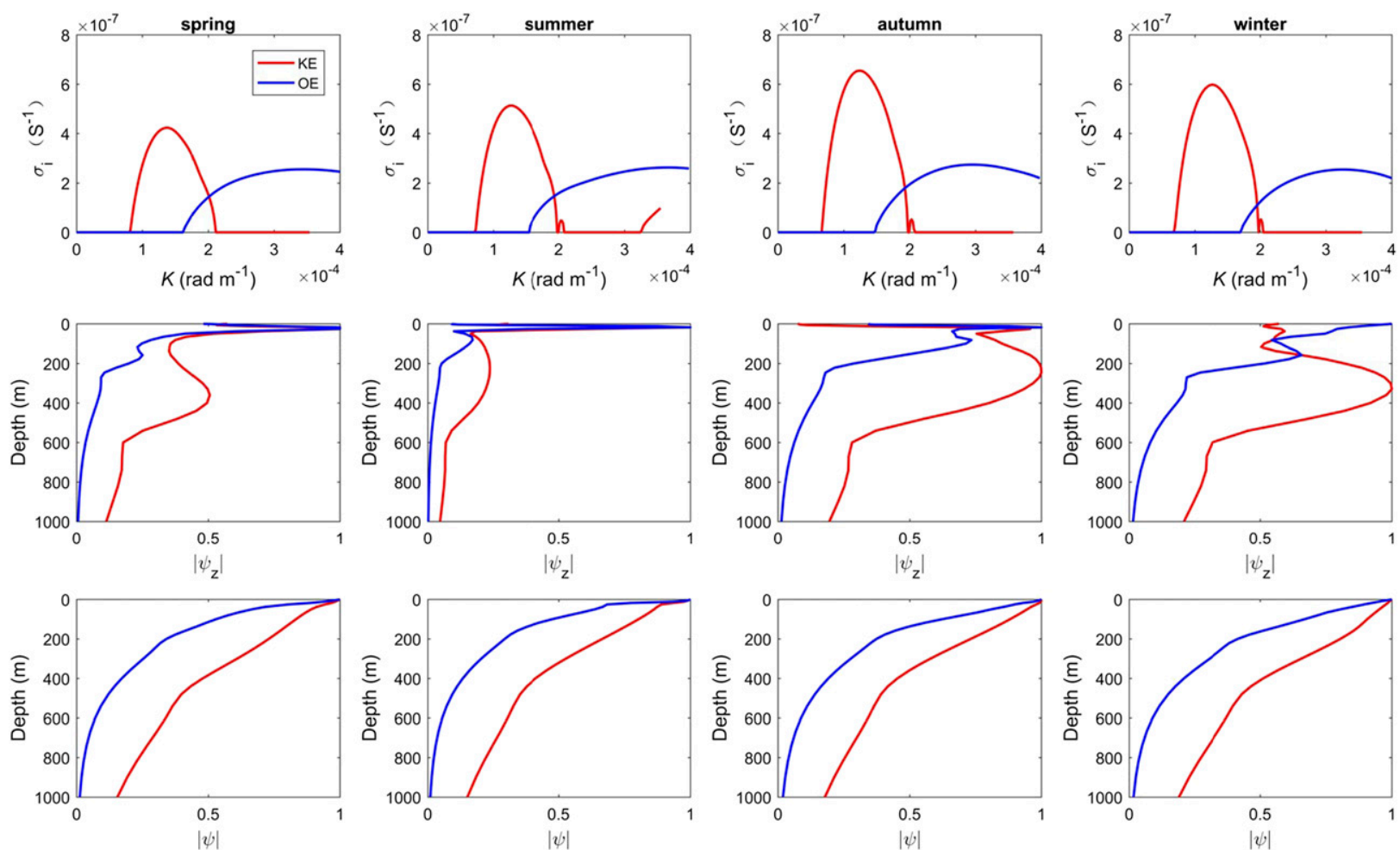

FIG. 8. (top) The growth rate as a function of zonal wavenumber $k$, (middle) the vertical structure of $\left|\partial \psi^{\prime} / \partial z\right|$, and (bottom) $\left|\psi^{\prime}\right|$ for the most unstable mode in different seasons.

vertical structure of $\left|\psi^{\prime}\right|$ for the most unstable mode. It is evident from Fig. 8 that the most unstable mode has a shallower vertical structure in the Oyashio extension than that in the Kuroshio extension. We further examine the vertical structure of $\left|\partial \psi^{\prime} / \partial z\right|$ that can be compared to the vertical profile of $\rho^{\prime} / \rho_{0}$ variance estimated from the FORA-WNP30 reanalysis (Fig. 6b). Depending on the seasons, $\left|\partial \psi^{\prime} / \partial z\right|$ in the Oyashio extension exhibits a peak within $50-200 \mathrm{~m}$ whereas it has a deeper and broader peak between 100 and $500 \mathrm{~m}$ in the Kuroshio extension. Such a feature is qualitatively consistent with the vertical profiles of $\rho^{\prime} / \rho_{0}$ variance. In addition, there is a strong peak within $0-20 \mathrm{~m}$ for $\left|\partial \psi^{\prime} / \partial z\right|$ in both the Kuroshio and Oyashio extensions. Such a near-surface peak is, however, absent in the vertical profiles of $\rho^{\prime} / \rho_{0}$ variance. We speculate that it might be an artifact of the QG dynamics based linear instability analysis as the QG dynamics cannot be applied to the near-surface regime where turbulent mixing is strong and background stratification is weak.

Both the background stratification (i.e., $N^{2}$ ) and density front are generally shallower in the Oyashio extension than in the Kuroshio extension (Figs. 5, 7). Which of these two factors is mainly responsible for the shallower baroclinically unstable modes in the Oyashio extension requires further analyses. To do so, we repeat the computation by exchanging the $N^{2}$ profiles between the Kuroshio and Oyashio extensions. As shown in Fig. 9, the vertical structures of $\left|\psi^{\prime}\right|$ and $\left|\partial \psi^{\prime} / \partial z\right|$ remain qualitatively unchanged. Therefore, the shallower vertical structure of mesoscale eddies in the Oyashio extension appears to be mainly attributed to the surface intensified density front in this region, lending supports to our conjecture.

\section{Conclusions and discussion}

In this study, we examine mesoscale SST dynamics in Kuroshio-Oyashio extension region based on satellite observations and a high-resolution reanalysis dataset (FORA-WNP30), focusing on the amplitude relationship between mesoscale SSHA and SSTA. The major conclusions are summarized as follows:

1) There is a clear mismatch between the spatial distributions of mesoscale SSHA and SSTA variances over the KOE region. The mesoscale SSHA variance peaks in the Kuroshio extension around $35^{\circ} \mathrm{N}$. In contrast, the enhanced mesoscale SSTA variance occurs well to the north of the Kuroshio extension with its maximum located along the Oyashio 

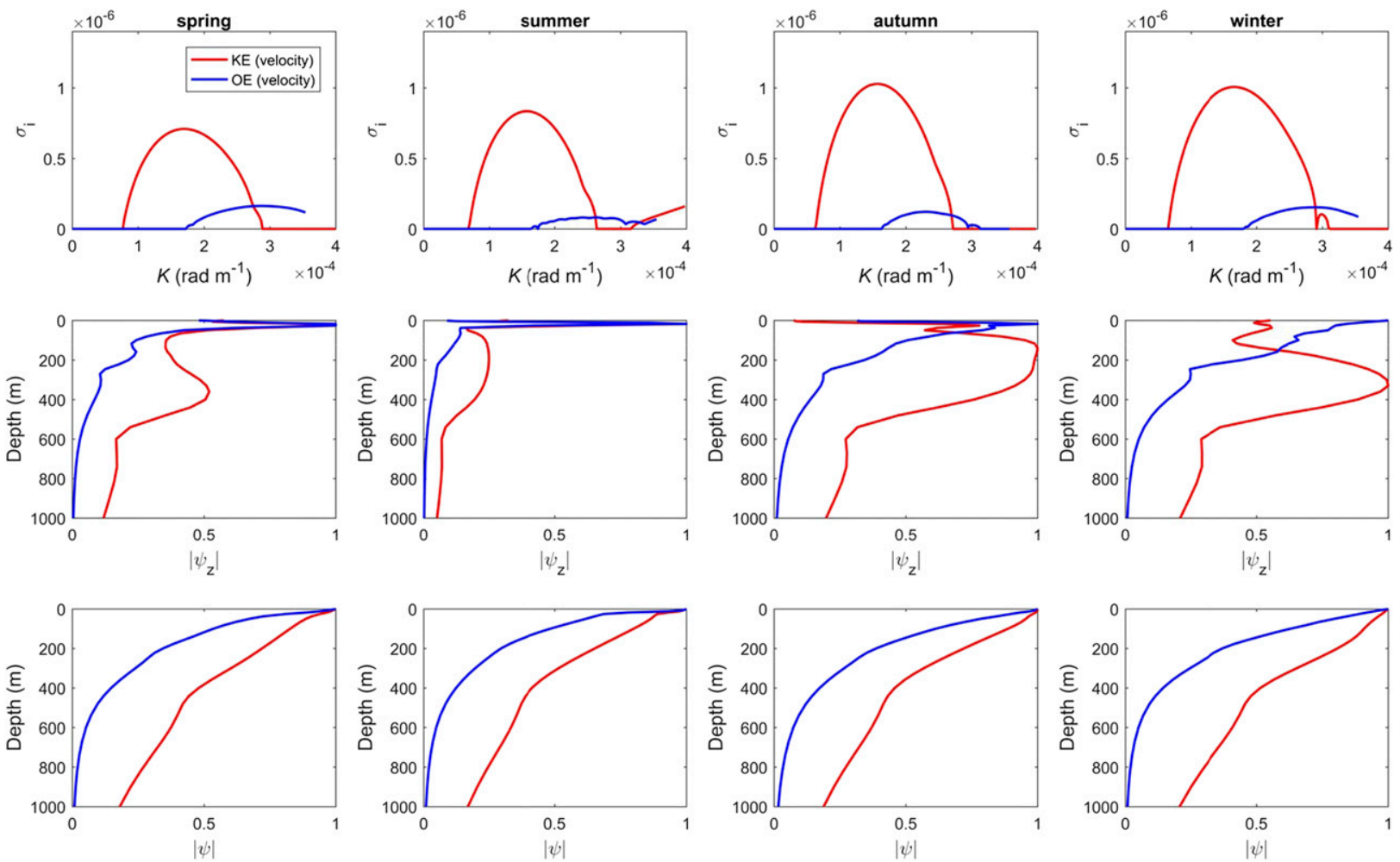

FIG. 9. As in Fig. 8, but computed by exchanging $N^{2}(z)$ between the Kuroshio and Oyashio extensions. Here the red lines represent the results based on $U(z)$ in the Kuroshio extension and $N^{2}(z)$ in the Oyashio extension, while the blue lines represent the results based on $U(z)$ in the Oyashio extension and $N^{2}(z)$ in the Kuroshio extension.

extension around $40^{\circ} \mathrm{N}$. Regression analyses reveal different H-T amplitude relationships between the Kuroshio extension $\left(145^{\circ}-160^{\circ} \mathrm{E}, 34^{\circ}-36^{\circ} \mathrm{N}\right)$ and Oyashio extension $\left(145^{\circ}-160^{\circ} \mathrm{E}, 39^{\circ}-41^{\circ} \mathrm{N}\right)$. The former has a regression coefficient of $1.8^{\circ} \mathrm{Cm}^{-1}$, while the latter has a much larger value of $6.2^{\circ} \mathrm{Cm}^{-1}$.

2) Theoretical analyses suggest that there are three main factors responsible for the stronger $\mathrm{H}-\mathrm{T}$ amplitude relationship in the Oyashio extension than in the Kuroshio extension. The first factor is the smaller thermal expansion coefficient due to the colder background SST. The second is the stronger salinity compensation effect that works against the contribution of the SSTA change to the SSDA change. These two effects work in concert, leading to the reduced sensitivity of SSDA changes to SSTA changes. The third one is the shallower vertical structure of mesoscale eddies.

3) The enhanced salinity compensation effect in the Oyashio extension is attributed to the strong surface salinity front there. A linear baroclinic instability analysis suggests that the shallower vertical structure of mesoscale eddies in this region is mainly due to the shallower density front.
It is generally thought that the ocean mesoscale eddyatmosphere interaction is most significant in the western boundary current extensions and Southern Ocean due to the presence of strong oceanic fronts and mesoscale eddy activities (Bryan et al. 2010; Frenger et al. 2013; Putrasahan et al. 2013; Bishop et al. 2017). What is masked by this well recognized concept is the ambiguity in the definition of mesoscale eddy activity. It is natural to define mesoscale eddy activity based on the SSHA from a pure ocean dynamics viewpoint. The results in this study, however, suggest that using the SSHA information alone to assess the mesoscale eddyatmosphere interactions is insufficient and can even be misleading as the strong mesoscale SSHA and SSTA variances do not necessarily coincide with each other due to the highly inhomogeneous amplitude relationship between the mesoscale SSHA and SSTA. For instance, when the SSHA alone is used to measure mesoscale eddy variability in the KOE region, the Kuroshio extension is the only region identified with energetic mesoscale eddies. However, the strongest mesoscale eddy-atmosphere interactions actually occur in the Oyashio extension where the mesoscale SSTA variance is the largest but with weak mesoscale SSHA 
variance. It is thus essential to incorporate the information of mesoscale SSHA and SSTA together when analyzing the mesoscale eddy-atmosphere interactions.

Acknowledgments. This work started during ZJ's postdoctoral training at TAMU partially supported by the U.S. National Science Foundation (NSF) Grant AGS-1462127. ZJ acknowledges the support from the Marine S\&T Fund of Shandong Province for Pilot National Laboratory for Marine Science and Technology (Qingdao) (2018SDKJ0102-7-7), NSFC Projects (41776006 and 41822601), and Fundamental Research Funds for the Central Universities 201841011 and 201812014. PC acknowledges the support from NSF AGS-1462127, NSFC 41490644 and 41490640, and China's National Basic Research Priorities Programmer (2013CB956204). We thank the Center for Earth Information Science and Technology (JAMSTEC)/Meteorological Research Institute (Japan Meteorological Agency) for providing the FORA-WNP30 reanalysis dataset. This is a collaborative project between the Ocean University of China (OUC), Texas A\&M University (TAMU), and the National Center for Atmospheric Research (NCAR) and is completed through the International Laboratory for High Resolution Earth System Prediction (iHESP) - a collaboration among the Qingdao National Laboratory for Marine Science and Technology Development Center, Texas A\&M University, and the National Center for Atmospheric Research.

\section{APPENDIX A}

\section{Relation between $H_{e}$ and Vertical Structure of Mesoscale Eddies}

To illustrate how $H_{e}$ is related to the vertical structure of mesoscale eddies, we compute the vertical profile of density anomaly induced by mesoscale eddies, using an eddy composite analysis. Mesoscale eddies are detected using the closed contour method based on SSH (Kurian et al. 2011). Several criteria were applied when applying the method to the daily SSH data in the KOE region: 1) the shape error of the closed contours should be below $60 \%, 2$ ) the eddy radius should be within $45-150 \mathrm{~km}$, and 3 ) the eddy amplitude should be larger than $1 \mathrm{~cm}$. Those closed contours that pass all the tests above are accepted as mesoscale eddies.

Once a mesoscale eddy is detected, its density anomaly is computed as the difference between the values in the eddy center (averaged within 0.5 radius) and along the eddy edge (averaged between 1 and 1.5 radius). To obtain the vertical profile of density anomaly induced by mesoscale eddies in a specific region, all density anomaly profiles in that area are

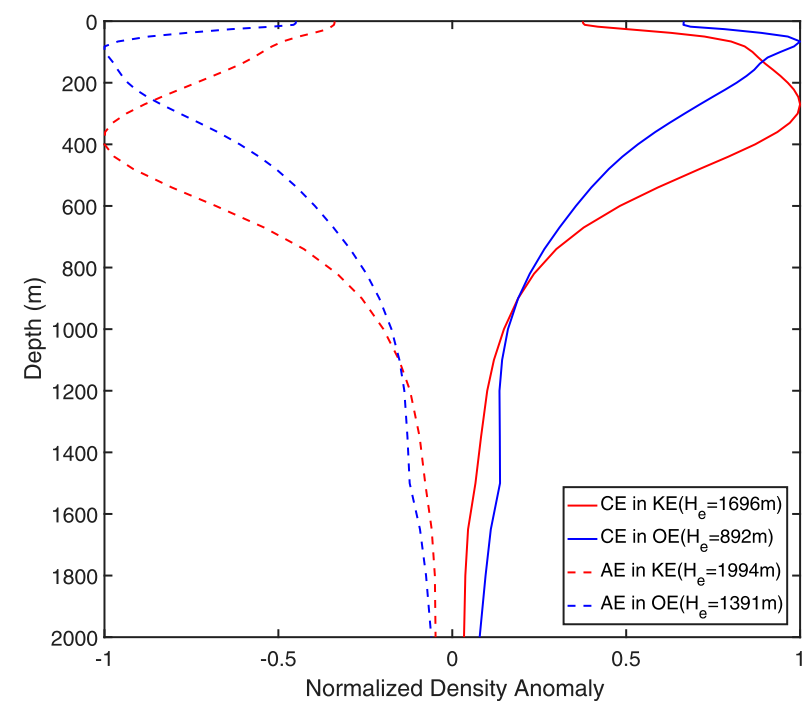

FIG. A1. Vertical profiles of mesoscale density anomaly and their associated $H_{e}$ in the Kuroshio extension (red) and Oyashio extension (blue), respectively. Profiles for cyclonic eddies (CE) and anticyclonic eddies (AE) are computed separately. Vertical profiles are normalized by their maximum magnitude to facilitate comparison.

first accumulated. Then, a composite analysis is performed to cyclonic and anticyclonic eddies, respectively.

Figure A1 shows the composite vertical profiles of the density anomaly induced by mesoscale eddies and the associated values of $H_{e}$ in the Kuroshio extension and Oyashio extension, respectively. There are two notable features. First, the value of $H_{e}$ increases as the density anomaly peaks at greater depth with smaller surface signals. Nevertheless, $H_{e}$ should not be treated as a direct measurement of mesoscale eddy depth. For instance, the value of $H_{e}$ of anticyclonic eddies in the Kuroshio extension is $1994 \mathrm{~m}$, whereas the density anomaly peaks within $200-600 \mathrm{~m}$ with negligible signals below $1000 \mathrm{~m}$. Second, there are noticeable differences between the values of $H_{e}$ derived from eddy composite analysis and those from regression analysis. This might be due to the fact that $\operatorname{Cov}\left(\int_{z_{r}}^{0} \rho^{\prime} d z, \rho_{s}^{\prime}\right) / \operatorname{Var}\left(\rho_{s}^{\prime}\right)$ is not mathematically equivalent to $E\left(\int_{z_{r}}^{0} \rho^{\prime} d z\right) / E\left(\rho_{s}^{\prime}\right)$ where Cov, Var, and $E$ denote the covariance, variance, and expectation operators, respectively. In addition, it also implies that not all the mesoscale anomalies could be captured by the eddy detection method.

\section{APPENDIX B}

\section{Derivation of Eq. (9)}

Assuming that the temperature is conserved during the fluids motions, the temperature anomalies relative to the background field can be computed as 


$$
\begin{aligned}
T^{\prime}\left(x+\xi_{x}, y+\xi_{y}, z+\xi_{z}, t\right)= & -\bar{T}\left(x+\xi_{x}, y+\xi_{y}, z+\xi_{z}\right) \\
& +\bar{T}(x, y, z),
\end{aligned}
$$

where $(x, y, z)$ is the initial position of fluids and $\left(\xi_{x}, \xi_{y}, \xi_{z}\right)$ is its displacement. Under the small amplitude assumption, Eq. (B1) can be linearized as

$$
T^{\prime}=-\frac{\partial \bar{T}}{\partial x} \xi_{x}-\frac{\partial \bar{T}}{\partial y} \xi_{y}-\frac{\partial \bar{T}}{\partial z} \xi_{z} .
$$

Provided that the fluids motion is nearly horizontal and $|\partial \bar{T} / \partial x| \ll|\partial \bar{T} / \partial y|$, Eq. (B2) can be approximated as

$$
T^{\prime}=-\frac{\partial \bar{T}}{\partial y} \xi_{y}
$$

Similarly, we have

$$
S^{\prime}=-\frac{\partial \bar{S}}{\partial y} \xi_{y}
$$

Combining Eqs. (B3) and (B4) yields

$$
S^{\prime}=\left(\frac{\partial \bar{S}}{\partial y} / \frac{\partial \bar{T}}{\partial y}\right) T^{\prime}
$$

Substituting Eq. (B5) into the equation of state the linearized equation of state $\rho_{s}^{\prime}=-\rho_{0}\left(\alpha T_{s}^{\prime}-\beta S_{s}^{\prime}\right)$ yields Eq. (9).

\section{REFERENCES}

Bishop, S. P., R. J. Small, F. O. Bryan, and R. A. Tomas, 2017: Scale dependence of midlatitude air-sea interaction. J. Climate, 30, 8207-8221, https://doi.org/10.1175/JCLI-D-17-0159.1.

Bryan, F. O., R. Tomas, J. M. Dennis, D. B. Chelton, N. G. Loeb, and J. L. McClean, 2010: Frontal scale air-sea interaction in high-resolution coupled climate models. J. Climate, 23, 62776291, https://doi.org/10.1175/2010JCLI3665.1.

Byrne, M. D., M. Münnich, M. I. Frenger, and N. Gruber, 2016: Mesoscale atmosphere ocean coupling enhances the transfer of wind energy into the ocean. Nat. Commun., 7, 11867, https:// doi.org/10.1038/ncomms11867.

Chelton, D. B., and S.-P. Xie, 2010: Coupled ocean-atmosphere interaction at oceanic mesoscales. Oceanography, 23, 52-69, https://doi.org/10.5670/oceanog.2010.05.

—, M. G. Schlax, M. H. Freilich, and R. F. Milliff, 2004: Satellite measurements reveal persistent small-scale features in ocean winds. Science, 303, 978-983, https://doi.org/10.1126/ science.1091901.

,,-- R. M. Samelson, and R. A. de Szoeke, 2007: Global observations of large oceanic eddies. Geophys. Res. Lett., 34, L15606, https://doi.org/10.1029/2007GL030812.

,-- , and — 2011: Global observations of nonlinear mesoscale eddies. Prog. Oceanogr., 91, 167-216, https://doi.org/ 10.1016/j.pocean.2011.01.002.
Cheng, Y. H., C. R. Ho, Q. N. Zheng, and N. J. Kuo, 2014: Statistical characteristics of mesoscale eddies in the North Pacific derived from satellite altimetry. Remote Sens., 6, 5164-5183, https://doi.org/10.3390/rs6065164.

Dong, C., J. C. McWilliams, Y. Liu, and D. Chen, 2014: Global heat and salt transports by eddy movement. Nat. Commun., 5, 3294, https://doi.org/10.1038/ncomms4294.

Dong, D., P. Brandt, P. Chang, F. Schutte, X. Yang, J. Yan, and J. Zeng, 2017: Mesoscale eddies in the northwestern Pacific Ocean: Three-dimensional eddy structures and heat/salt transports. J. Geophys. Res., 122, 9795-9813, https://doi.org/ 10.1002/2017JC013303.

Frenger, I., N. Gruber, R. Knutti, and M. Münnich, 2013: Imprint of Southern Ocean eddies on winds, clouds and rainfall. Nat. Geosci., 6, 608-612, https://doi.org/10.1038/ngeo1863.

Gaube, P., D. B. Chelton, R. M. Samelson, M. G. Schlax, and L. W. O'Neill, 2015: Satellite observations of mesoscale eddyinduced Ekman pumping. J. Phys. Oceanogr., 45, 104-132, https://doi.org/10.1175/JPO-D-14-0032.1.

Hausmann, U., and A. Czaja, 2012: The observed signature of mesoscale eddies in sea surface temperature and the associated heat transport. Deep-Sea Res. I, 70, 60-72, https://doi.org/ 10.1016/j.dsr.2012.08.005.

Itoh, S., and I. Yasuda, 2010: Characteristics of mesoscale eddies in the Kuroshio-Oyashio Extension Region detected from the distribution of the sea surface height anomaly. J. Phys. Oceanogr., 40, 1018-1034, https://doi.org/10.1175/2009JPO4265.1.

Iwao, T., M. Endoh, N. Shikama, and T. Nakano, 2003: Intermediate circulation in the northwestern North Pacific derived from subsurface floats. J. Oceanogr., 59, 893-904, https:// doi.org/10.1023/B:JOCE.0000009579.86413.eb.

Jayne, S. R., and J. Marotzke, 2002: The oceanic eddy heat transport. J. Phys. Oceanogr., 32, 3328-3345, https://doi.org/10.1175/ 1520-0485(2002)032<3328:TOEHT>2.0.CO;2.

Kurian, J., F. Colas, X. Capet, J. C. Williams, and D. B. Chelton, 2011: 2011: Eddy properties in the California Current System. J. Geophys. Res., 116, C08027, https://doi.org/10.1029/ 2010JC006895.

Liu, X., P. Chang, J. Kurian, R. Saravanan, and X. Lin, 2018: Satellite-observed precipitation response to ocean mesoscale eddies. J. Climate, 31, 6879-6895, https://doi.org/10.1175/ JCLI-D-17-0668.1.

Ma, X., and Coauthors, 2015: Distant influence of Kuroshio eddies on North Pacific weather patterns? Sci. Rep., 5, 17785, https:// doi.org/10.1038/srep17785.

_ - and Coauthors, 2016: Western boundary currents regulated by interaction between ocean eddies and the atmosphere. Nature, 535, 533-537, https://doi.org/10.1038/nature18640.

_- P. Chang, R. Saravanan, R. Montuoro, H. Nakamura, D. Wu, X. Lin, and L. Wu, 2017: Importance of resolving Kuroshio front and eddy influence in simulating the North Pacific storm track. J. Climate, 30, 1861-1880, https://doi.org/10.1175/ JCLI-D-16-0154.1.

McGillicuddy, D. J., Jr., and Coauthors, 1998: Influence of mesoscale eddies on new production in the Sargasso Sea. Nature, 394, 263-266, https://doi.org/10.1038/28367.

Putrasahan, D. A., A. J. Miller, and H. Seo, 2013: Isolating mesoscale coupled ocean-atmosphere interactions in the Kuroshio Extension region. Dyn. Atmos. Oceans, 63, 60-78, https:// doi.org/10.1016/j.dynatmoce.2013.04.001.

Qiu, B., 1999: Seasonal eddy field modulation of the North Pacific subtropical countercurrent: TOPEX/POSEIDON observations and theory. J. Phys. Oceanogr., 29, 2471-2486, 
https://doi.org/10.1175/1520-0485(1999)029<2471:SEFMOT> 2.0.CO;2.

- , and S. Chen, 2004: Seasonal modulations in the eddy field of the South Pacific Ocean. J. Phys. Oceanogr., 34, 1515-1527, https://doi.org/10.1175/1520-0485(2004)034<1515: SMITEF $>2.0 . \mathrm{CO} ; 2$.

- and - 2005: Variability of the Kuroshio Extension jet, recirculation gyre and mesoscale eddies on decadal time scales. J. Phys. Oceanogr., 35, 2090-2103, https://doi.org/ 10.1175/JPO2807.1.

, and _ 2010: Interannual variability of the North Pacific subtropical countercurrent and its associated mesoscale eddy field. J. Phys. Oceanogr., 40, 213-225, https://doi.org/10.1175/ 2009JPO4285.1.

Reynolds, R. W., T. M. Smith, C. Liu, D. B. Chelton, K. S. Casey, and M. G. Schlax, 2007: Daily high-resolution-blended analyses for sea surface temperature. J. Climate, 20, 5473-5496, https://doi.org/10.1175/2007JCLI1824.1.

Sasaki, Y. N., and S. Minobe, 2015: Climatological mean features and interannual to decadal variability of ring formations in the Kuroshio Extension region. J. Oceanogr., 71, 499-509, https:// doi.org/10.1007/s10872-014-0270-4.

Scott, R. B., and F. Wang, 2005: Direct evidence of an oceanic inverse kinetic energy cascade from satellite altimetry. J. Phys. Oceanogr., 35, 1650-1666, https://doi.org/10.1175/JPO2771.1.

Siegel, D. A., D. J. McGillicuddy Jr., and E. A. Fields, 1999: Mesoscale eddies, satellite altimetry, and new production in the Sargasso Sea. J. Geophys. Res., 104, 13 359-13 379, https:// doi.org/10.1029/1999JC900051.

Stammer, D., 1997: Global characteristics of ocean variability estimated from regional TOPEX/POSEIDON altimeter measurements.
J. Phys. Oceanogr., 27, 1743-1769, https://doi.org/10.1175/ 1520-0485(1997)027<1743:GCOOVE > 2.0.CO;2.

_ 1998: On eddy characteristics, eddy transports, and mean flow properties. J. Phys. Oceanogr., 28, 727-739, https://doi.org/ 10.1175/1520-0485(1998)028<0727:OECETA > 2.0.CO;2.

Sun, W., C. Dong, R. Wang, Y. Liu, and K. Yu, 2017: Vertical structure anomalies of oceanic eddies in the Kuroshio Extension region. J. Geophys. Res. Oceans, 122, 1476-1496, https://doi.org/10.1002/2016JC012226.

Usui, N., and Coauthors, 2017: Four-dimensional Variational Ocean Reanalysis: A 30-year high-resolution dataset in the western North Pacific (FORA-WNP30). J. Oceanogr., 73, 205233, https://doi.org/10.1007/s10872-016-0398-5.

Vallis, G. K., 2017: Atmospheric and Oceanic Fluid Dynamics. Cambridge University Press, 964 pp.

von Storch, J. S., C. Eden, I. Fast, H. Haak, D. Hernaìndez-Deckers, E. Maier-Reimer, J. Marotzke, and D. Stammer, 2012: An estimate of the Lorenz energy cycle for the World Ocean based on the $1 / 10^{\circ}$ STORM/NCEP simulation. J. Phys. Oceanogr., 42, 2185-2205, https://doi.org/10.1175/JPO-D-12-079.1.

Yang, H., B. Qiu, P. Chang, L. Wu, S. Wang, Z. Chen, and Y. Yang, 2018: Decadal variability of eddy characteristics and energetics in the Kuroshio Extension: Unstable versus stable states. J. Geophys. Res. Oceans, 123, 6653-6669, https://doi.org/ 10.1029/2018JC014081.

Yasuda, I., 2003: Hydrographic structure and variability in the Kuroshio-Oyashio transition area. J. Oceanogr., 59, 389-402, https://doi.org/10.1023/A:1025580313836.

Zhang, Z., W. Wang, and B. Qiu, 2014: Oceanic mass transport by mesoscale eddies. Science, 345, 322-324, https://doi.org/ 10.1126/science. 1252418 . 